\title{
Urban Fire Spread Modelling and Simulation Using Cellular Automaton with Extreme Learning Machine
}

\author{
J.C.J. Patac ${ }^{1}$, A.J.O. Vicente ${ }^{1, *}$ \\ ${ }^{1}$ Department of Computer Science, University of the Philippines Cebu, Philippines - (jjpatac, aovicente)@up.edu.ph
}

\author{
Commission IV
}

KEY WORDS: Urban Fire Spread Simulation, Cellular Automaton, Extreme Learning Machine

\begin{abstract}
:
Urban fire continues to be a persistent disaster, especially with the proliferation of highly dense urban settlements. As a response, several measures were established to help mitigate the losses caused by fire including simulating the fire spread. The cellular automaton system has been widely used to simulate the complex process of fire development along with Physics-based models. A data-driven approach has been rarely employed. This paper presents the result of incorporating machine learning techniques to the existing cellular automaton based urban fire spread models. Specifically, instead of manually calculating the ignition probability of each cell in the automaton, the Extreme Learning Machine (ELM) was used to learn the ignition probability from the historical data. After building the model, its performance was evaluated using the data collected from the four fires in Basak, Lapu-Lapu City. By using a confusion matrix to compare the actual and the predicted values, the Burned Actual - Burned Predicted relationship was derived. Results suggest that the proposed method can effectively describe the development of fire, and the model accuracy is quite good (i.e., the Burned Actual - Burned Predicted relationship ranges from $78 \%$ to 83\%). Lastly, the study was able to demonstrate the possibility of using a data-driven approach in creating a simple cellular automaton fire spread simulation model for urban areas. Further studies utilizing more fire incident data on with varying properties is recommended.
\end{abstract}

\section{INTRODUCTION}

Fire is a natural process that has an essential contribution to the ecosystem. However, fire can become very risky and even deadly depending on various circumstances. Because of that, different mitigation and preventive measures have been established to control its negative effects. It is important to develop these measures as they could serve as the basis for devising plans for future firefighting activities. Given these, various methods have been introduced as tools for formulating these strategies, such as fire danger estimation systems (Vasilakos et al., 2009), fire loss assessment systems (Zhao, 2011), and fire spread modelling and simulation systems (Bertinshaw, Guesgen, 2002). Virtual simulation of the spread of the fire was considered since then by many researchers as an integral instrument for the fire departments to create effective plans for fire disaster mitigation.

There have been many models created to predict the spread of fire. The majority of these models target forest or wildfires although there are targeted at urban fires. These models produce good results and can definitely predict fire spread. To date, the field of study continues to grow. Existing cellular automata fire spread models on urban areas are assumed to be non-flexible because of the fact that the models are created for specific areas. In addition, there is currently no urban fire spread model that uses cellular automaton and machine learning together which was considered a promising approach in forest fire spread modeling (Zheng et al., 2017). On the other hand, physicalbased models, although promising, are considered too complex because of the fact that the model requires extensive research and high-end resources to operate (Himoto et al., 2008). This situation of finding the balance between the accuracy of the model and the complexity of the results leads to more time and expense to researchers. With the focus of further improving the simulation results of the existing models without compromising the simplicity through integrating the methodologies of these existing representations, an urban fire spread model that could possibly yield good results of fire spread simulation can be created.

Generally, this study aimed to explore the development of a new approach to predicting fire spread by utilizing existing Cellular Automata fire spread models and incorporating Machine Learning techniques to identify the ignitability of cells.

This paper reports the results of training and experiments involving four fire incidents in Barangay Basak, Lapu Lapu City, Philippines.

\subsection{Cellular Automaton Models}

With the goal of making firefighting activities more effective, different fire spread models were created and proposed. One of the models proposed to simulate the spread of fire uses cellular automaton as a framework. In a cellular automaton, each cell in the system is restricted to local neighborhood interaction only. Thus, the automaton is one of the simplest methods, time-wise and memory-wise, that can represent a phenomenon, such as traffic congestion (Yuen, Kay, 2010). But in spite of its simplicity, the cellular automaton can easily model physical systems and processes where local interactions are involved and produce astonishing results. Therefore, the employment of the framework is considered as the most common approach for fire modeling (Ohgai et al., 2004). That being said, there are variations of the model ranging from the traditional cellular automaton to cellular automaton with integrated machine learning techniques to further improve the accuracy of the results. 


\subsection{Forest Fire Spread Models}

One of the earliest fire spread models that use cellular automaton was devised and proposed by Karafyllidis and Thanailakis in 1997. The model focuses on simulating the spread of fire for both homogeneous and heterogeneous forests. Karafyllidis and Thanailakis (1997) created their own transition rules for the eight (8) neighboring cells, which can serve as one of the deciding factors of how the model works. The authors also created their own algorithm that can determine the behavior of fire at a certain time. Ultimately, Karafyllidis and Thanailakis (1997) adjusted their algorithm so that it can easily model the effects of weather and topography into the spreading of fire. This can be considered as the greatest achievement of the research because weather and topography are considered as two of the most important factors in the spreading of fire, especially in a forest setting (Cheney et al., 1993). According to the authors' simulations, the results produced by the algorithm were in good agreement with the experience of fire spreading in real forests. This work of Karafyllidis and Thanailakis (1997) was also used as the basis for other succeeding forest fire spread models. One of the most notable fire spread models is a modification of Karafyllidis' and Thanailakis' work by Hernández Encinas et al., (2007). Instead of the linear front presented by the former, a circular spreading of the fire front was shown. The authors did this by modifying the transition algorithm used for diagonal neighboring cells. As a result, the modified model proposed by Hernández Encinas et al. (2007) is more realistic and precise compared to the original model.

Another spread cellular automaton model was proposed by Wang Xuehua et al., (2016). Wang Xueha et al. (2016) drastically improved the effects of wind in the previous model. This improvement allowed the model to reach new heights in simulating the spread of fire and yield better results than the base model.

In 2016, Zheng et al. improved the use of cellular automaton by incorporating machine learning techniques in model creation. This method promises to solve the problem pointed out in the previous forest fire spread models; i.e. human errors (Zheng et al., 2016). The authors also created their own cell states and local transition rules but the rules are very similar to the existing models. Because the model is still in its exploratory stage, some of the important fire driving forces were not present in the model; it only considered wind speed and direction. Despite the fact that it lacks the important parameters, the simulation accuracy can range between $59 \%$ and $82 \%$, which is better than that of the previously reported studies in most cases (Zheng et al., 2016).

Despite producing good simulation results, models that are based on discrete values can most likely have discrepancies (Hernández Encinas et al., 2007). One of the main issues of the presented models is that the weather variable incorporated only refers to the velocity and direction of the wind. The models did not include several factors related to weather such as the weather condition itself (e.g. rainy, sunny. etc.), humidity or air temperature, and the time of the day. Some of these variables are labeled as primary driving forces of the propagation of fire especially in the forest setting (Williams, 1977; Pitts, 1990; Baeza et al., 2002). Another problem with most of the presented models is that the local transition rules used are subject to human errors. In other words, the performance and efficiency of their algorithm heavily depend on the way the authors implemented it. This means that in the process of creating the rules, comprehensive studies about the physical principle of fire are involved (Zheng et al., 2016). Although some discrepancies are present in the models, they can still be useful references for future studies about the spreading of fire. Hence, this research was inspired by the work of Zheng et al. (2016) wherein a datadriven approach was incorporated in creating the model.

\subsection{Urban Fire Spread Models}

Cellular automaton has already been applied to fires in the urban setting. Takizawa (2000) studied fire spread modelling using stochastic cellular automaton in a city setting. Like the previous forest fire propagation models, the reason that the cellular automaton was chosen to be its basis is that it can imitate complex processes in such a simple manner. What separates this study to the other works of literature is the use of stochastic cellular automaton (Takizawa, 2000). This means that the new entities' states are chosen based on some probability distributions. In other words, this model can also be viewed as a discrete-time random dynamical system. Looking into the results of the simulation, Takizawa (2000) concluded that the model can simulate the actual spread of fire quite well despite its simplicity.

One major setback with the model of Takizawa (2000) is that it assumes that the building materials are all wooden. This means that the model created was not applicable to almost all urban areas but only to the area of focus which was in Wakamatsucho, Nagata Ward. Another problem with this model is that it does not incorporate the most important factor in fire spread, which is the wind speed and direction. As a result, the created model is not flexible enough to model various urban settings; in fact, it just adds inaccuracy.

Another cellular automaton fire spread model that uses urban setting as its subject area was developed to help communitybased planning for disaster mitigation (Ohgai et al., 2004). Compared to the fire spread model of Takizawa (2000), Ohgai et al. (2004) added several cell states and incorporated wind speed and direction into the model in a unique manner. Also, Ohgai et al. (2004) proposed that the ideal size of the cells in a cellular automaton model for urban areas is $3 \times 3$ meters. The authors also implemented a sub-model simulating the effects of firefighting activities which proves to be useful for a much better simulation of fire propagation especially in diverse areas (Alexandridis et al., 2011). As an outcome, it was shown that the simulation results can reproduce the actual fire spreading records approximately. However, although the simulation results were better compared to the work of Takizawa (2000), it remains that the model presented by Ohgai et al. (2004) also assumes that the building materials are uniform. Therefore, just like the Takizawa model, this model is assumed to be obsolete.

Nevertheless, this research still considered these studies as a vital part for devising a better model. The fact that the models were focused on an urban setting can greatly influence the study itself. Also, the studies mentioned several parameters that can prove useful when modelling a real urban area. Examples of these parameters are building materials, building height, building density, cell size, etc (Takizawa, 2000; Ohgai et al., 2004; Gao et al., 2008). Therefore, this study shall refer specifically to the works of Ohgai et al. (2004) and Gao et al. (2008) together with the work of Zheng et al. (2016) to create a representation for urban areas.

\subsection{Physical-based Models}

Aside from cellular automaton, there are also systems that use physical principles to model the spread of fire. One of the famous models that use this methodology was devised by Rothermal (1972). This model uses different mathematical 
equations to predict the propagation of fire in wildland fuels (Rothermal, 1972). Its main concept is to create an equation based on the laws of Physics. The equations for the heat required for ignition, propagating flux, reaction intensity, and the effects of wind and slope were all considered in formulating the model. As a result, the outputs were highly accurate that the model was used as a basis for appraising fire spread and intensity in the National Fire-Danger Rating System.

Another physical-based implementation of the fire spread simulation was proposed by Himoto and Tanaka in 2003. This model focuses on predicting the fire propagation in urban areas. Like the Rothermal (1972) model, this system also uses the physical principle to simulate the spreading of fire in an individual building. These individual building fires are then accumulated to create a realistic simulation of urban fire spread (Himoto, Tanaka, 2003). It also incorporates the wind variable into the model. The model is still at its exploratory stage but based on the results, it is heading in the right direction and has high potential. Accordingly, the representations have a high potential in producing more accurate results. However, there are relatively few studies regarding the subject matter. One of the possible reasons for this is that it is too specific to create a general model, thus, increasing the complexity of the system. Another reason for that is its nature; where multiple mathematical equations are converted into computer algorithms, a high-performance resource is needed to cater to the lengthy computations of the model (Himoto, Tanaka, 2003).

\section{METHODOLOGY}

The main focus of this study is to implement the existing algorithms for urban fire spread simulation using cellular automaton and integrate machine learning techniques in its implementation. Essentially, fire spread will be simulated using cellular automaton using wind speed and direction following the work of Ohgai et al. (2004) and Gao et al. (2008). The probability of the cell catching fire is estimated using machine learning of houses/buildings' properties. The use of machine learning in estimating this probability for urban settings has rarely been explored.

The research design is divided into three main sections: (a) Dataset preparation, (b) Modeling and Simulation, and (c) Validation.

\subsection{Dataset Preparation}

Meteorological and Fuel or Driving Force data were collected for the study. In particular, wind speed and direction (meteorological) were used to simulate the direction and rate of spread of fire while building construction material, fire load (driving forces) and presence of firefighting facilities were used to estimate the probability of the unit to catch fire.

Each sample in the dataset was manually processed since some of the features were not suitable inputs in a neural network machine learning. The samples were manually tagged with the appropriate class label, i.e. 0 for not burned and 1 for burned. QGIS, an open-source desktop tool for processing geospatial data, was used to preprocess the raw information. After the preliminary processing, 6,944 distinct building footprints were generated as the training dataset. Of which, 4,387 or $63 \%$ of the training dataset were extracted from burned areas and 2,557 or $37 \%$ were extracted from unburned areas. Preprocessed data from Sitio Balutan Tangke and Sitio Lanao Danao served as testing dataset while data from Sitio Tamiya and Sitio San Roque will be used as training dataset.

2.1.1 Preprocessing Fire Load Types: Fire Load pertains to the type of material for the basic commodities (i.e. bed, sofa, table, etc.) found inside the house. The different fire load types can be wood, plastic or foam. The counts of each fire load type found in the household/building were used as values for the feature. These were eventually normalized to get a value between zero and one. Fire load types were treated equally which means that no weights were assigned for each type.

2.1.2 Preprocessing Fire Fighting Facilities: In contrast to fire load types, the data for firefighting facilities were encoded individually to indicate the number of each firefighting facility. The values were also normalized resulting in a value between zero and one.

2.1.3 Mapping the Buildings to Cells: The shapefile that contains the target building footprints were mapped in a grid of $3 \times 3$-meter cells as shown Figure 1. The data of each building footprint were then distributed to the cells that it intersects. The footprint outside of the fire extent, i.e. those that were not burned, were also include in the dataset. The number of not burned footprints varied from one fire incident to another. As a rule, buildings that are unlikely to catch fire such as those from across the street or too far away from the origin are no longer included. Making sure that the number of unburned footprints that are included in the dataset is in proportion with the number of burned footprints is considered as well.

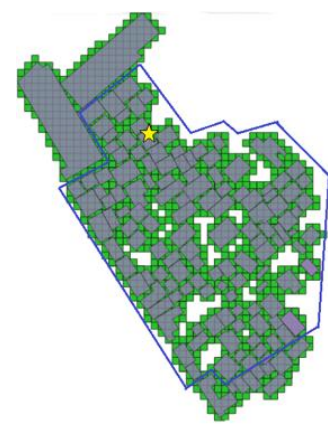

Figure 1. Tamiya Mapping of Buildings to Cells

In Figure 1, each box represents a building footprint while the blue polygon represents the extent for fire in the area. The star indicates the origin of fire. The grid cells are represented as green cells in the background.

For each cell or sample, the values of its driving force were labeled as the input (i.e., $\mathrm{x}_{\mathrm{i}}$ ) of the ELM model. If the sample was extracted from a burned area, its class label was set to 1 . Otherwise, it was set to 0 . The final dataset would look like Table 1.

\begin{tabular}{|c|c|c|c|c|c|c|c|c|c|}
\hline \multicolumn{4}{|c|}{ Materials } & \multicolumn{3}{|c|}{ Fire Load Type } & \multirow{2}{*}{$\begin{array}{l}\mathbf{H} \\
\mathbf{E} \\
\mathbf{I} \\
\mathbf{G} \\
\mathbf{H} \\
\mathbf{T}\end{array}$} & \multirow{2}{*}{ 窇 } & \multirow{2}{*}{$\begin{array}{l}\mathbf{B} \\
\mathbf{U} \\
\mathbf{R} \\
\mathbf{N} \\
\mathbf{E} \\
\mathbf{D}\end{array}$} \\
\hline $\begin{array}{l}7 \\
0 \\
0 \\
3\end{array}$ & $\begin{array}{l}\vec{\Xi} \\
\ddot{\Xi} \\
\ddot{0}\end{array}$ & $\stackrel{\pi}{\mathbb{0}}^{\frac{\pi}{2}}$ & $\frac{\mathscr{J}}{\frac{\pi}{2}}$ & $\begin{array}{l}7 \\
0 \\
0 \\
3\end{array}$ & $\frac{0}{\stackrel{0}{3}}$ & 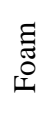 & & & \\
\hline 1 & 1 & 0 & 0 & 0.074 & 0.25 & 0.0 & 1 & 0.0 & 1 \\
\hline 0 & 1 & 1 & 0 & 0.0 & 0.0 & 0.0 & 2 & 1.0 & 0 \\
\hline- & - & - & - & - & - & - & - & - & - \\
\hline
\end{tabular}

Table 1. Sample Dataset 


\subsection{Fire Spread Simulation and Ignitability Modelling}

In this study, the works of Ohgai et al. (2004) and Gao et al. (2008) were considered as the blueprint of the model but instead of manually calculating the ignition probability of each cell, a data-driven approach was used. Furthermore, the overall process of the model could be described by the following flowchart:

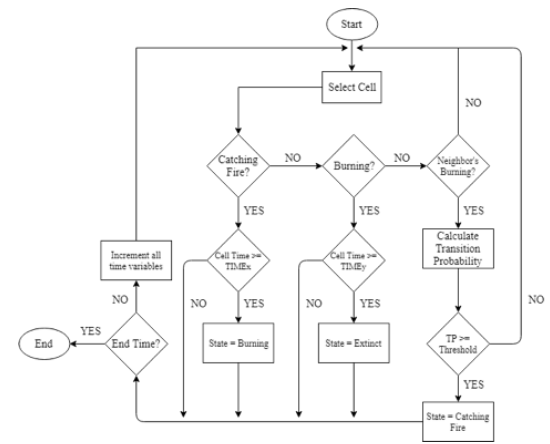

Figure 2. Fire Spread Simulation Flow Chart

2.2.1 Characteristics of the Cell: Gao et al. (2008) mentioned that there are three main factors that can affect the spread of fire in an urban area. Therefore, these factors were considered as the attributes of a cell in the cellular automaton:

3. Building condition - composed of building materials, floor area, and height of a building. These attributes are the main factors for the possibility of a building burning.

4. Weather condition - composed of wind velocity and direction. This relates to the direction, range, and the possibility of spreading (external factor).

5. Characteristics of the area - composed of vacant land and road. These are mainly considered as the factor for spread control.

As mentioned previously, each cell in the automaton represents a feature in the dataset which holds the pieces of information derived from the buildings that intersect the cell.

Moreover, in modelling the spread of fire using cellular automaton, the size of the cell is assumed as one of the most vital parts of the framework (Gao et al., 2008). The smaller the size of the cell, the more detailed simulation results can be obtained. However, the downside of this feature is that it increases the calculation time and the volume of data needed. Therefore, the size of the cell must be set properly to maintain a balance between the results and the complexity of the model. In this study, the size of the cell is set at 3 by 3 meters $(3 \times 3 \mathrm{~m})$ following the research of Ohgai et al. (2004).

5.1.1 Neighborhood: Like the models of Ohgai et al. (2004) and Gao et al. (2008), the neighborhood type of this study is dependent on the speed of the wind (see Figure 2). According to Ohgai et al. (2004), this adjustable neighborhood is based on the idea of the limit of distance that fire can spread which was presented by Jirou and Kobayashi.
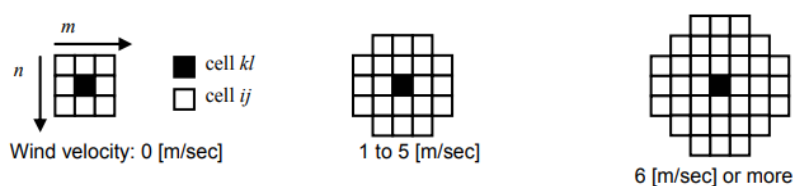

Figure 3. Neighborhood in the model (Ohgai et al., 2004)
5.1.2 States of the Cell: To minimize the complexity of implementing the model, this study chose to work on a squarelattice and the usual 2D square grids were used as cells in the framework. Additionally, the states of a cell were adapted from the works of Ohgai et al. (2004) and Gao et al. (2008). Therefore, each square in the grid can be described by the following states:

State 0: Unburnable; A cell containing no fuel

State 1: Not burning; A cell containing fuel has the possibility to ignite

State 2: Catching fire; A cell containing fuel is burning but has no ability to spread fire

State 3: Burning; A cell containing fuel is burning and has the ability to spread fire

State 4: Extinction; A cell containing fuel has already been burned

5.1.3 Transition Rules: In order for a cell in an automaton to change between the aforementioned states, a finite set of local transition rules is required. In this research, these rules were established as follows:

Rule 1: A cell without any fuel (State 0) is unburnable and never changes during the simulation period.

Rule 2: A burned cell (State 4) remains burned in the succeeding time steps.

Rule 3: A burning cell (State 3) must be updated into the burned state (State 4) if the current burning time of the cell is equal or greater than a defined time, $t_{y}$.

Rule 4: A burning cell with no ability to spread fire (State 2) must be updated into the burning state (State 3) if the current burning time of the cell is equal or greater than a certain time, $t_{x}$. Rule 5: An unburned cell containing fuel (State 1) must be updated to a burning state (State 2) if one or more of its neighboring cells is burning and its transition probability is higher than a random probability threshold.

Following the researches of Ohgai et al. (2004) and Gao et al. (2008), the equation for the transition probability in this study was given as:

$$
\mathrm{P}_{\mathrm{i}, \mathrm{j}}=\alpha \cdot p(i, j)_{t} \cdot W(i, j)^{\beta} \cdot p\left(t_{c k}\right)
$$

where $p(i, j)_{t}$ is the igniting probability of the cell considering the fire's driving forces in that cell and $W(i, j)$ is the wind factor. $p\left(t_{c k}\right)$ refers to the ability of the burning cell to cause fire spreading. $\boldsymbol{\alpha}$ is an adjustable parameter whose value is changed to wind effects such as slowing of the spreading velocity and $\boldsymbol{\beta}$ is also an adjustable parameter which determines the direction and range of spreading. Finally, $\mathrm{P}_{\mathrm{i}, \mathrm{j}}$ refers to the transition probability of a cell or the ability of a cell to catch fire.

5.1.4 Building the Igniting Probability Model: In the works of Ohgai et al. (2004) and Gao et al. (2008), the ignition probability of a cell was manually calculated. The calculation also considered the building structure parameters or building materials. Instead of manual calculation, this study used a machine learning technique to predict the ignition probability values of the cells.

In this research, the Extreme Learning Machine (ELM) technique was used (see Figure 4). This machine learning technique was proven to be a simple and efficient learning algorithm for single-hidden layer feedforward neural networks (Huang et al., 2006; Yang et al., 2011; Zheng, et al. (2017). 


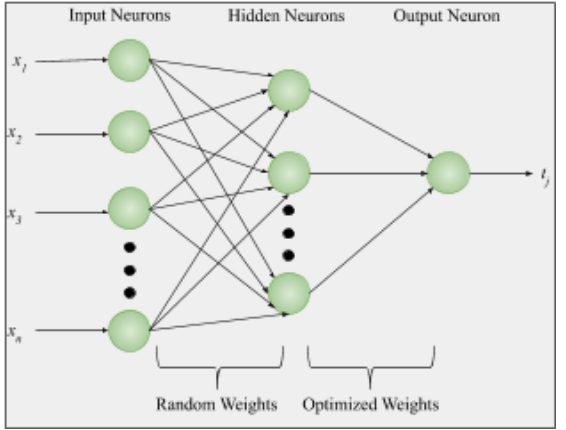

Figure 4. ELM Model (Yang, et al, 2011)

In the ELM model, given $\mathrm{N}$ arbitrary distinct samples, the objective is to find a quantitative relationship between the inputs and the output. Each cell's data of the driving forces of fire were labeled as inputs and the cell's igniting probability was considered as the output of the model.

5.1.5 Effects of Neighboring Wind: In this work, the effect of wind in a cell (see Figure 5) was also derived from the study of Ohgai et al. (2004) and Gao et al. (2008).

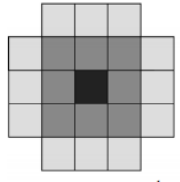

(a) 0 to $1 \mathrm{~m} \cdot \mathrm{s}^{-1}$

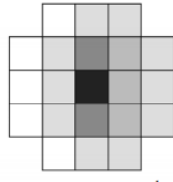

(b) 2 to $5 \mathrm{~m} \cdot \mathrm{s}^{-1}$

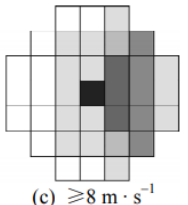

(c) $\geqslant 8 \mathrm{~m} \cdot \mathrm{s}^{-1}$
Figure 5. Effects of Western Wind (Gao et al., 2008)

As shown in Figure 5 the number of cells that could possibly burn increases as the speed of the wind increases. In addition, if the wind speed is strong enough, the cells on the leeward side take a higher fire spreading probability than the cells on the windward side.

5.1.6 Spreading the Time Step: This study highlighted two important time factors that should be observed. First is the time required that a cell in State 2 (catching fire state) should change to State 3 (burning and can cause the fire to spread). This time variable $\left(t_{x}[\mathrm{~min}]\right)$ was calculated using the equation given by Ohgai et al. (2004) and Gao et al. (2008):

$$
t_{x}=(3+3 a / 8+8 d / D) /(1+0.1 v)
$$

The second time variable that was considered in the model is the time $\left(t_{v}\right.$ [min] $)$ until a cell burns after catching fire is defined as follows (Ohgai et al., 2004):

$$
t_{y}=(w / 5.5) /\left(A_{w} \sqrt{ } H / A_{f}\right)
$$

It is also important to note that these time variables were used for calculating the value of $p\left(t_{c k}\right)$ - the ability of the burning cell to spread the fire. The value of $p\left(t_{\text {ckl }}\right)$ gradually increases the longer the burning time, $t_{k l}$, of the cell is. Similarly, it is assumed that the longer a material is exposed to heat, the higher its chances of igniting.

\subsection{Model Validation}

Since the output of the Extreme Learning Machine is an igniting probability, there is no ground truth to test the performance of the model because there are only two classes in the dataset (i.e.
1 and 0 ). Thus, the results of the machine learning model were plugged into the overall system and a fire spread simulation was performed. This means that the performance of the simulation was also the basis of the accuracy of the machine learning model.

In this research, the confusion matrix was used. It is a quantitative method of characterizing classification accuracy in the form of a table that relates the classification result and the actual values. Fire spread was simulated in the two test communities - Sitio Tangke Balutan and Sitio Lanao Danao, within the reported duration of the fire incidents. Using this metric, five quantitative measurements were obtained after the simulation - (1) percentage of burned actual-burned predicted; (2) percentage of burned actual-not burned predicted; (3) percentage of not burned actual-burned predicted; (4) area of actual burned in $\mathrm{km}^{2}$; and (5) area of burned predicted in $\mathrm{km}^{2}$.

\section{DISCUSSIONS AND CONCLUSIONS}

\subsection{Dataset}

As mentioned in the previous sections, the features of each sample are composed of building materials, building height, fire load types, and firefighting facilities. It was also mentioned that the majority of the building structures in the target areas were all residential and the type of construction materials used was generally light. Furthermore, a comparison of the features in all study areas and a summary of the features for both the training data and testing data is shown in Table 2 and Table 3.

\begin{tabular}{|c|c|c|c|c|}
\hline & \multicolumn{2}{|c|}{ Training } & \multicolumn{2}{c|}{ Testing } \\
\hline Features & Tamiya & $\begin{array}{c}\text { San } \\
\text { Roque }\end{array}$ & $\begin{array}{c}\text { Balutan } \\
\text { Tangke }\end{array}$ & $\begin{array}{c}\text { Lanao } \\
\text { Danao }\end{array}$ \\
\hline Wood & $91.48 \%$ & $78.41 \%$ & $54.13 \%$ & $82.06 \%$ \\
\hline Cement & $52.99 \%$ & $91.60 \%$ & $79.34 \%$ & $93 \%$ \\
\hline Metal & $0.56 \%$ & $9.85 \%$ & $0 \%$ & $36.32 \%$ \\
\hline Plastic & $1.19 \%$ & $7.32 \%$ & $0 \%$ & $0 \%$ \\
\hline Wooden & $4.20 \%$ & $3.22 \%$ & $11.64 \%$ & $3.88 \%$ \\
\hline Plastic & $8.68 \%$ & $1.84 \%$ & $6.89 \%$ & $5.08 \%$ \\
\hline Foam & $3.98 \%$ & $1.36 \%$ & $3.31 \%$ & $5.47 \%$ \\
\hline $\begin{array}{c}\text { Firefighting } \\
\text { Facility }\end{array}$ & $0 \%$ & $2.93 \%$ & $0 \%$ & $0 \%$ \\
\hline
\end{tabular}

Table 2. Comparison of features of the four study areas

Table 2 shows that Sitio Tamiya is mostly composed of wooden than cemented structures. In contrary, the rest of the sitios (i.e. San Roque, Balutan Tangke, and Lanao Danao) are mostly composed of cement than wood. Furthermore, Table 2 shows that all four study areas have similar values on Plastic-made structures. It was mentioned previously that the buildings involved in the fire incidents were all residential types which imply that the construction materials used are also similar to each other.

In terms of the relationship between the fire load types of the four sitios, Table 2 implies that all four areas have similar fire load types distribution. Additionally, the firefighting facilities of the four places are all close to zero. Again, this is due to the fact that almost all the structures in the fire sites are residential which means that fire extinguisher, smoke sensor, etc., are hardly present. 


\begin{tabular}{|c|c|c|}
\hline Features & Training & Testing \\
\hline Wood & $84.63 \%$ & $72.39 \%$ \\
\hline Cement & $73.22 \%$ & $88.27 \%$ \\
\hline Metal & $5.43 \%$ & $23.75 \%$ \\
\hline Plastic & $4.40 \%$ & $0 \%$ \\
\hline Wooden & $3.69 \%$ & $6.57 \%$ \\
\hline Plastic & $5.10 \%$ & $5.70 \%$ \\
\hline Foam & $2.61 \%$ & $4.72 \%$ \\
\hline Fire Fighting Facility & $1.54 \%$ & $0 \%$ \\
\hline
\end{tabular}

Table 3. Summary of features of the Training and Testing Data

Moreover, the four study areas were grouped into two to produce the training and testing dataset. The training data was composed of sitio Tamiya and sitio San Roque as these two fire incidents have the largest burned area covered, which means that a larger dataset for training could be derived. Consequently, the remaining two study areas were used to test the performance of the model.

\subsection{Performance Evaluation Results}

The data from Sitio Tamiya and San Roque were used for training the neural network model. The model was then used as a factor in the fire simulation among other factors such as wind speed, wind direction, etc. for all four fires used in this study. Figures 7 and 8 show the results of the fire spread simulation in the four study areas. The figures also present a comparison with the actual extent or perimeter of the fire. For each study area, the simulation results exhibit an acceptable agreement with the actual fire extent.

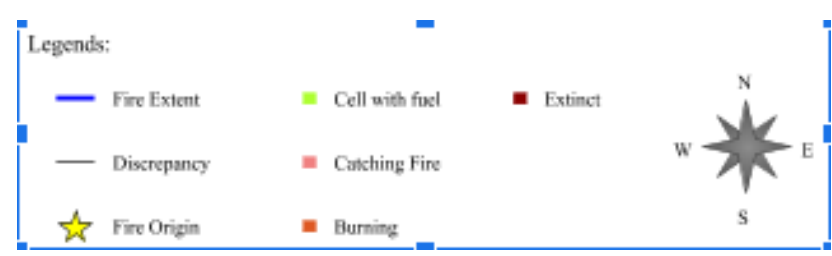

Figure 6. Fire Simulation Results Legends

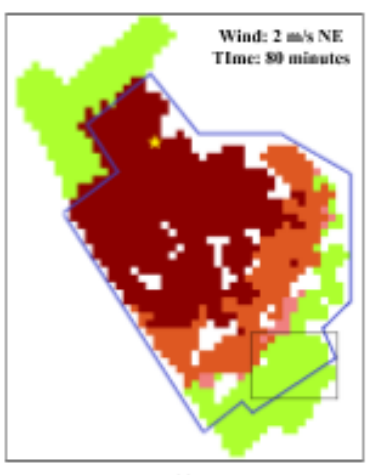

(a)

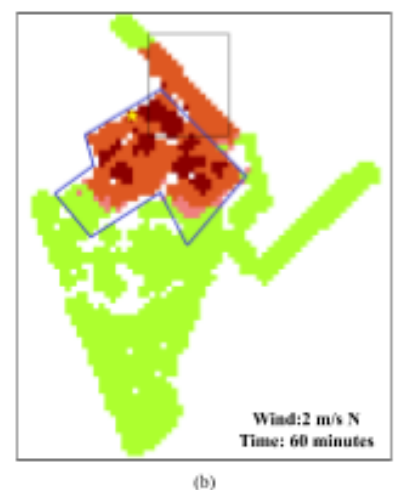

Figure 7. Simulation Results on Training Set, Tamiya (a) and San Roque (b)
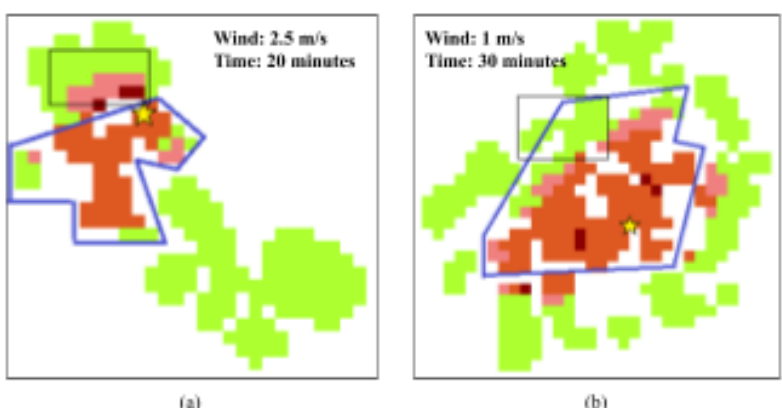

Figure 8. Simulation Results on Test Set in Balutan Tangke (a) and Lanao Danao (b)

\begin{tabular}{|l|c|c|c|c|}
\hline & \multicolumn{2}{|c|}{ Training } & \multicolumn{2}{c|}{ Testing } \\
\hline & Tamiya & $\begin{array}{c}\text { San } \\
\text { Roque }\end{array}$ & Balutan & $\begin{array}{l}\text { Lanao } \\
\text { Danao }\end{array}$ \\
\hline $\begin{array}{l}\text { Burned Actual - } \\
\text { Burned Predicted } \\
{[\%]}\end{array}$ & 82.84 & 83.26 & 79.29 & 78.07 \\
\hline $\begin{array}{l}\text { Burned Actual - Not } \\
\text { Burned Predicted } \\
{[\%]}\end{array}$ & 17.16 & 16.74 & 20.71 & 21.93 \\
\hline $\begin{array}{l}\text { Not Burned Actual - } \\
\text { Burned Predicted } \\
{[\%]}\end{array}$ & 0.45 & 2.2 & 1.5 & 2.46 \\
\hline $\begin{array}{l}\text { Actual Burned Area } \\
{\left[\mathrm{m}^{2}\right]}\end{array}$ & 8262 & 3915 & 504 & 1494 \\
\hline $\begin{array}{l}\text { Predicted Burned } \\
\left.\text { Area [m }{ }^{2}\right]\end{array}$ & 6844.5 & 3259.8 & 399.6 & 1166.4 \\
\hline
\end{tabular}

Table 4. Quantitative comparison between simulation results and actual values

From a quantitative perspective, Table 4 shows the Burned Actual - Burned Predicted percentage ranges between $78 \%$ and $83 \%$. The table also displays that the Burned Actual - Burned Predicted relationship between the training and testing dataset only differs by $3 \%$ to $5 \%$. This implies that the proposed model has a consistent performance for both seen and unseen data. One factor for this high precision is because both the building materials of the training and testing set are considered to be generally similar.

\subsection{Simulation Discrepancies}

Parts of the simulation results highlighted with the black boxes were the discrepancies of the results. For both San Roque and Lanao Danao areas, it can be observed that the fire reached beyond the expected extent (see Figure 7 (b) and Figure 8 (b)). It's highly probable that this deviation is because of existing high walls and firewalls which were not included in the data collection. It is also possible that the topography of the place, which was not considered in this study, played a role in shaping the actual fire extent. According to Hernández Encinas et al. (2007), fire shows a smaller rate of spread when it descends a downward slope than when it climbs up an upward slope. Thus, neglecting this factor in the proposed model could lead to model discrepancies and inaccuracy.

Furthermore, in a layman's perspective, the simulation results should have exceeded the actual fire extent simply because there were no firefighting activities integrated in the model. Instead, it can be perceived that there are areas inside the actual 
fire boundary that did not ignite. One contributor to this is the fact that the data used were post-fire information. It is possible that the reconstructed establishments were designed to be less ignitable compared to the pre-fire buildings. This leads to a lower rate of fire spread than the actual disaster. Another important factor that may possibly explain the deviation is the spotting effect. Although it rarely happens in urban fires, spotting effect could possibly ignite a new fire in the leeward side of the wind. This phenomenon could actually extend the real fire boundary a little further. Additionally, it is assumed that in an actual fire, the faster the ignition time of the fire load, the faster it can cause fire spreading. As mentioned earlier, the fire load weights in this study were considered equal which could also be the reason for the low rate of spread.

In practice, the simulation of the fire's spreading pattern could not really exactly match with the actual fire behavior since not all fire records can meet the necessary demands (Huang et al., 2016). An example would be the wind velocity data which were generally observed at sparse monitoring sites. This means that the accurate wind velocity data on the place of fire cannot be obtained. This small inaccuracy could already lead to the dissimilarity of the predicted and actual fire spreading. In addition to that, the proposed model was constructed using a cellular automaton system which is limited by the pre-defined cell states, transition rules, and the shape of the cell. This study chose to work on a traditional square-lattice instead of using an irregular cellular automaton to represent the buildings. This implies that the proposed model is just an approximation of the actual physical system which also means that the simulation results could certainly vary. Furthermore, not all states of fire were represented in the model. According to Josh (2010), there are generally four stages of fire: incipient, growth, fully developed, and decay. In this study, the growth stage was not included since it was considered as the shortest phase of the fire development process. Thus, this constraint could also contribute to the dissimilarity of the simulation results and actual fire.

\subsection{Conclusions and Recommendations}

Urban fire is an expensive disaster not just in the Philippines but all over the world. In this study, a new urban fire spread model was proposed by modifying an existing cellular automaton model and integrating ELM to calculate the ignition probability of each cell. The analysis was conducted in four distinct study areas located in Basak, Lapu-Lapu City. Results suggest that the proposed method can effectively describe the spreading of fire, and the model accuracy is quite good (i.e., the Burned Actual Burned Predicted relationship ranges from $78 \%$ to $83 \%$ ). Therefore, this study demonstrated the possibility of using a data-driven approach in creating a simple cellular automaton fire spread model for urban areas.

Furthermore, the dataset used in this study was considered small-sized due to some constraints. Thus, it is highly recommended to add more data in order to improve the model and make it more suitable for simulating communities with different profiles. With more data, a better model can be trained. In addition, it is recommended to test the model in more recent fires, i.e. fires after enumeration, to confirm the contribution of construction materials as a primary factor in the probability of a house or any urban establishment to catch fire. Lastly, it is highly recommended to implement a fire fighting sub-model to realistically simulate the spreading of fire.

\section{ACKNOWLEDGEMENTS}

This research is supported by the Firecheck Project, a DOSTPCIEERD project of the University of the Philippines Cebu.

\section{REFERENCES}

Alexandridis, A., Russo, L., Vakalis, D., Bafas, G. V., Siettos, C. I., 2011. Wildland fire spread modelling using cellular automata: evolution in large-scale spatially heterogeneous environments under fire suppression tactics. International Journal of Wildland Fire, 20(5), 633.

Baeza, M. J. , De Luís, M., Raventós, J., Escarré, A., 2002. Factors influencing fire behaviour in shrublands of different stand ages and the implications for using prescribed burning to reduce wildfire risk. Journal of Environmental Management, 65(2), 199-208.

Bertinshaw, D., Guesgen, H. W., 2002. Physical Approximations for Urban Fire Spread Simulations. In Proceedings of the Seventeenth International Florida Artificial Intelligence Research Society Conference, Miami Beach, Florida, USA. 783-788.

Cheney, N., Gould, J., Catchpole, W., 1993. The Influence of Fuel, Weather and Fire Shape Variables on Fire-Spread in Grasslands. International Journal of Wildland Fire, 3(1), 31.

Gao, N., Weng, W., Ma, W., Ni, S., Huang, Q., Yuan, H., 2008. Fire spread model for old towns based on cellular automaton. Tsinghua Science and Technology, 13(5), 736-740.

Hernández Encinas, A., Hernández Encinas, L., Hoya White, S., Martín del Rey, A. , Rodríguez Sánchez, G., 2007. Simulation of forest fire fronts using cellular automata. Advances in Engineering Software, 38(6), 372-378.

Himoto, K., Akimoto, Y., Hokugo, A., Tanaka, T. , 2001. Risk and Behavior of Fire Spread in A Densely-built Urban Area. Fire Safety Science, 9, 267-278.

Himoto, K.,Tanaka, T., 2003. A Physically-Based Model for Urban Fire Spread. Fire Safety Science, (7), 129-140.

Huang, G-B., Zhu, Q.Y., Siew, C.K., 2006. Extreme learning machine: Theory and applications. Neurocomputing, 70(1-3), 489-501.

Josh, 2010 Sept. The 4 Stages of a Fire | Journey To Firefighter. Retrieved from https://journeytofirefighter.com/4-stages-of-afire/

Karafyllidis, I., Thanailakis, A., 1997. A model for predicting forest fire spreading using cellular automata. Ecological Modelling, 99(1) 87-97. https://doi.org/10.1016/S03043800(96)01942-4.

Ohgai, A., Gohnai, Y., Ikaruga, S., Murakami, M.,Watanabe, K., 2004. Cellular Automata Modeling For Fire Spreading As a Tool to Aid Community-Based Planning for Disaster Mitigation. In Recent Advances in Design and Decision Support Systems in Architecture and Urban Planning, J. P. Van Leeuwen and H. J. P. Timmermans, Eds. Dordrecht: Springer Netherlands, 193-209. 
Pitts, W. M., 1990. Wind Effects on Fire. Progress in Energy and Combustion Science, 17(2). 83-134. https://doi.org/10.1016/0360-1285(91)90017-H.

Rothermal, R., 1972. A mathematical model for predicting fire spread in wildland fuels. Res. Pap. INT-115. Ogden, UT: U.S. Department of Agriculture, Intermountain Forest and Range Experiment Station.

Takizawa, A., Yamada, A., Kawamura, H., Tani, A., 2000. Simulation of Spreads of Fire on City Site BY Stochastic Cellular Automata. In Proc.,12th World Conference on Earthquake Engineering, pp.2334-1.

Vasilakos, C., Kalabokidis, K., Hatzopoulos, J., Matsinos, I. , 2009. Identifying wildland fire ignition factors through sensitivity analysis of a neural network. Natural Hazards 50, 1 (Jul. 2009) 125-143.

Williams, F. A., 1977. Mechanisms of fire spread. Symposium (International) on Combustion, 16(1), 1281-1294.

Xuehua, W., Chang, L., Jiaqi, L., Xuezhi, Q., Ning, W., Wenjun, Z., 2016. A cellular automata model for forest fire spreading simulation. In 2016 IEEE Symposium Series on Computational Intelligence (SSCI), Athens, Greece, 1-6.

Yang, H., Xu, W., Zhao, J., Wang, D., Dong, Z., 2011. Predicting the probability of ice storm damages to electricity transmission facilities based on ELM and Copula function. Neurocomputing, 74(16), 2573-2581.

Yuen, A., Kay, R., 2010. Applications of Cellular Automata. p. 20. Retrieved from

http://www.cs.bham.ac.uk/ rjh/courses/NatureInspiredDesign/2 009-10/StudentWork/Group2/design-report.pdf

Zhao, S., 2011. Simulation of Mass Fire-Spread in Urban Densely Built Areas Based on Irregular Coarse Cellular Automata. Fire Technology, 47, 3 (Jul. 2011), 721-749. DOI= https://doi.org/10.1007/s10694-010-0187-4

Zheng, Z., Huang, W. \& Li, S. \& Zeng, Y., 2017. Forest fire spread simulating model using cellular automaton with extreme learning machine. Ecological Modelling. 348. 33-43.

10.1016/j.ecolmodel.2016.12.022. 